\title{
A pedagogia hospitalar como campo de formação e atuação profissional
}

\section{The hospital pedagogy as a field of training and professional activities}

\author{
${ }^{1}$ Maria Terezinha Bretas Vilarino tevilarino@yahoo.com.br \\ ${ }^{1}$ Edmarcius Carvalho Novaes \\ ${ }^{1}$ Ariádine Soares de Oliveira
}

\section{RESUMO}

O artigo tem por intuito identificar a importância do atendimento pedagógico de crianças hospitalizadas e os impactos dessa atuação para a formação profissional de educadores pedagogos. Trata-se de uma revisão bibliográfica e relato de experiência sobre a temática, relacionada às vivências no estágio curricular supervisionado obrigatório em educação não-escolar, realizado no Hospital Municipal de Governador Valadares /MG, no segundo semestre do ano de 2015, por graduandas do Curso de Pedagogia da Universidade Vale do Rio Doce - UNIVALE. Conclui-se que é importante uma atuação pedagógica a fim de proporcionar a educação para crianças em períodos de internação nas pediatrias hospitalares enquanto direito assegurado por lei, bem como se faz necessário problematizar os avanços e desafios da formação profissional de pedagogos para a atuação na Pedagogia Hospitalar.

Palavras-chave: Capacitação de Professores. Educação Infantil. Educação de Pacientes como Assunto. Serviço Hospitalar de Educação.

\begin{abstract}
The aim of the research is to identify the importance of the pedagogical care of hospitalized children and the impacts of this professional activity on the professional training of pedagogical educators. This is a bibliographical review and experience report on the subject, related to the experiences in the compulsory supervised curricular internship in non-school education, held in the Hospital Municipal de Governador Valadares/MG, in the second half of 2015, by graduates of the Pedagogy of the Universidade Vale do Rio Doce - UNIVALE. It is concluded that a pedagogical action is important in order to provide education for children in hospitalization periods in the hospital pediatrics as a right guaranteed by law, as well as it is necessary to problematize the advances and challenges of the professional formation of pedagogues for the performance in Pedagogy Hospitalar.
\end{abstract}

Keywords: Teacher Training. Child Rearing. Patient Education as Topic. Education Department, Hospital. 


\section{INTRODUÇÃO}

A maioria dos cursos de Pedagogia prepara o profissional para atuar no espaço escolar. No entanto, sabe-se que sua atuação excede a sala de aula, o que confirma a necessidade de sua presença em diversos ambientes para contribuir na melhoria de processos educativos e de convivências estabelecidos ou que venham a se constituir.

Durante a graduação em Pedagogia na Universidade Vale do Rio Doce - UNIVALE, estuda-se a atuação do pedagogo também em outros espaços, ditos como "não escolares", na disciplina de "Educação Social”, o que proporciona um suporte teórico para investigar a importância do profissional, a partir de sua prática profissional no campo da Pedagogia Hospitalar. Entende-se que nesta área de atuação materializa-se práticas pedagógicas com foco em sujeitos e grupos que vivenciam contextos de vulnerabilidades específicas, e que necessitam de intervenções educativas. Quando tais práticas de educação social ocorrem no contexto de saúde, trata-se da Pedagogia Hospitalar (Pinel, 2015).

Já a experiência obtida durante o estágio curricular obrigatório não escolar permite a continuidade dos estudos referentes à atuação do pedagogo e a sua importância para os pacientes e demais profissionais inseridos no contexto hospitalar, ao se vivenciar todas as questões intrínsecas existentes neste campo profissional. Através das vivências no hospital pode-se percebê-lo como um espaço físico apropriado para o desenvolvimento das atividades pedagógicas, e que o relacionamento com os demais profissionais é uma barreira a ser vencida, uma vez que muitos desconhecem o trabalho do pedagogo.

De outro lado, não há uma aceitação da prática profissional por parte dos responsáveis pelos pacientes, por não saberem que a continuidade da educação para a criança internada é um direito garantido por lei, ou mesmo por acharem o trabalho desnecessário. De igual forma, pode-se perceber a importância de se problematizar já na formação pedagógica a necessidade de se (re)pensar um currículo para atuação do pedagogo também para este espaço profissional.

Assim, o objetivo geral desse trabalho foi refletir sobre a importância da atuação do profissional pedagogo para o atendimento das crianças hospitalizadas e para a pediatria hospitalar, a partir de um relato de experiência de graduandas em Pedagogia.

\section{METODOLOGIA}

Metodologicamente, este artigo possui natureza qualitativa, cujos procedimentos metodológicos são a revisão bibliográfica e o relato de experiência, a partir de dados registrados em diário de bordo durante prática formativa vivenciada em um Hospital Municipal, em Governador Valadares - MG, em cumprimento ao estágio curricular obrigatório de educação não escolar, no quinto período do Curso de Pedagogia, correspondente ao segundo semestre do ano de 2015.

Esse trabalho seguiu os princípios éticos contidos na Declaração de Helsinki (1964, reformulada em 1975, 1983, 1989, 1996 e 2000), da World Medical Association (www.wma.net/e/policy/b3.htm).

\section{O DIREITO À EDUCAÇÃO DA CRIANÇA HOSPITALIZADA}

Espera-se que a criança quando hospitalizada receba um atendimento que atenda às suas necessidades físicas, afetivas e educativas. Neste sentido, é necessário conhecer os direitos referentes à educação de crianças hospitalizadas. Um deles, é o direito ao atendimento pedagógico durante esse processo de internação. Neste sentido, a Política Nacional de Educação Especial (1994) determina a obrigatoriedade de um “(...) ambiente 
hospitalar que possibilita o atendimento educacional de crianças e jovens internados que necessitam de educação especial e que estejam em tratamento hospitalar”. (Brasil, 1994).

Já a Resolução do CONANDA - Conselho Nacional dos Direitos da Criança e do Adolescente, $n^{\circ} 41$, de 13 outubro de 1995, estabelece vinte direitos das crianças e adolescentes hospitalizados. Dentre eles, destacamos o item nove: "direito de desfrutar de alguma forma de recreação, programas para a saúde, acompanhamento do currículo escolar durante a sua permanência hospitalar” (Brasil, 1995).

A implementação de classe hospitalar também é um direito da criança hospitalizada visando o segmento dos conteúdos escolares, afim de não acarretar prejuízos na formação escolar. De acordo com o Ministério da Educação (2002), denomina-se classe hospitalar como

(...) o atendimento pedagógico-educacional que ocorre em ambientes de tratamento de saúde, seja na circunstância de internação, como tradicionalmente conhecida, seja na circunstância do atendimento em hospital-dia e hospital-semana ou em serviços de atenção integral à saúde mental. (Brasil, 2002, p.13)

Outra obrigatoriedade, segundo a Lei Federal $n^{0} .11 .104 / 2005$, é a instalação de brinquedotecas em hospitais com atendimento pediátrico, que as define como "espaço provido de brinquedos e jogos educativos, destinados a estimular as crianças e seus acompanhantes a brincar" (Brasil, 2005).

Entende-se que o brincar é uma forma de a criança desenvolver o cognitivo, a habilidade motora - o que reforça a importância e necessidade da brinquedoteca. Ressalta-se que os hospitais que não se adequarem à essa lei podem ser passíveis de punição, pois há previsão de “(...) advertência, interdição, cancelamento da licença ou multa para os hospitais que não se adaptarem à nova norma.” (Matos e Mugiatti, 2014, p. 150).

Nesse sentido, as leis visam garantir que toda criança possua todas as oportunidades educativas para que não haja danos no seu desenvolvimento e aprendizado durante o período de internação. No entanto, embora as leis estejam em vigor, o direito de fato, muitas vezes, não é efetivado. A ausência de um profissional que possa atender a este serviço e as más condições físicas das unidades hospitalares, não possibilitam que a criança receba o atendimento pedagógico educacional que lhe é de direito. Matos e Mugiatti (2014) afirmam: "No Brasil, a grande maioria dos hospitais não possuem atendimento ao escolar hospitalizado. Ainda não há um reconhecimento satisfatório no sentido de que as crianças e os jovens hospitalizados têm o direito à educação” (2014, p. 48).

Por outro lado, o fato dos profissionais da saúde e uma parcela da sociedade não (re)conhecerem este atendimento, dificulta a presença e atuação do pedagogo no ambiente hospitalar.

A conscientização sobre políticas públicas direcionadas à criança e adolescentes é essencial para que haja mudanças no cenário hospitalar em relação ao atendimento pedagógico. É necessário implementação de estratégias políticas e pedagógicas de gestão hospitalar para que a criança hospitalizada disponha da assistência educacional, o que passa pelo acatamento das leis, pela formação profissional em saúde, e pela sensibilização de todos envolvidos.

\section{RESULTADOS E DISCUSSÕES}

\section{1 A convergência entre educação e saúde}

A lei que ampara a criança hospitalizada no seu direito de continuidade do acompanhamento profissional de seu desenvolvimento sóciocognitivo e escolar está também associada à convergência entre os dois campos: o 
da educação e o da saúde. Embora conceitualmente ambos possuam particularidades específicas existe uma forte necessidade de diálogo no campo da prática. Para além da condição aqui colocada em pauta, o direito à continuidade do processo educativo da criança hospitalizada, tanto os profissionais da saúde como os profissionais da educação atuam em áreas que lhes exigem sensibilidade e disposição pedagógica, de um lado, e um entendimento sistêmico sobre os processos de saúde-doença, por outro. Tanto na escola como em espaços de promoção da saúde o cuidado e a educação estão associados, como aponta Maranhão ao destacar que o cuidado se apresenta como o elo entre as áreas da saúde e da educação:

O ato de cuidar expressa tanto as práticas sociais de promoção da saúde quanto de educação das crianças. Por isso não podemos dissociar o cuidado com a saúde das atividades consideradas educativas, embora os procedimentos de cuidado possam exigir conhecimentos de áreas diferentes daquelas que dão suporte às ações pedagógicas (Maranhão, 2000, p. 122).

Esse sentido atribuído ao cuidado, por Maranhão (2000), nos remete a um conceito de saúde mais abrangente do que aquele que tradicionalmente pensa a saúde com um enfoque puramente biológico. Tal tendência (biológica) pode restringir a atuação médica ao acompanhamento do quadro clínico, ao controle nutricional e das doenças transmissíveis, à elaboração de normas de higiene e alimentar, entre outras medidas curativas. Entretanto, embora essas ações sejam indicadores de saúde (e de doença) imprescindíveis num ambiente hospitalar, entendemos que não são o bastante para garantirem o desenvolvimento integral das crianças hospitalizadas (Maranhão, 2009). Neste caso é importante considerar as atuais discussões sobre o conceito de saúde, que preconizam elementos biopsicossociais como modeladores dos processos de produção da saúde e/ou doença (Batistella, 2007).

Em 1948, quando foi criada, a Organização Mundial de Saúde (OMS) cunhou o conceito de saúde, associando à ausência de enfermidade: "Saúde é o mais completo bem-estar físico, mental e social, e não apenas a ausência de enfermidade”. Muitas controvérsias e discussões se seguiram, desde então, devido à polissemia do termo (Scliar, 2007, p. 37-38). Em nossos dias já é patente o reconhecimento de que o conceito acima, não responde aos diversos ditames e condicionamentos psicológicos, culturais e sociopolíticos que acompanham os processos de adoecimento e de cura. O novo sentido dado à saúde - conveniando fatores biológicos ou patogênicos com fatores biopsicossociais e outros condicionantes, também muda a forma de os serviços de saúde pública lidar com suas contingências ${ }^{2}{ }^{3}$.

É a partir dessa nova abordagem, mais integralista (Brasil, 2000; Batistella, 2007; Scliar, 2007), que aproximamos a área da saúde com a área da educação para se compreender de forma integral as necessidades humanas, focando, nesse artigo, em sujeitos crianças e adolescentes que precisam de atenção médica hospitalar.

A superação do conceito puramente biológico sobre os processos de saúde/doença, o reconhecimento do direito da criança (ou adolescente) hospitalizada de ter continuidade nos processos de aprendizagem e sociabilidade iniciados na escola, a garantia que a lei dá para esses casos, o reconhecimento dessas mesmas crianças (e adolescentes) como sujeitos que protagonizam suas vidas a partir de incontáveis mediações, são já suficientes para defendermos, como Maranhão (2000, p. 116) que ações especializadas (didático-pedagógicas) "podem ser planejadas conjuntamente com os serviços de saúde locais e realizadas em parceria com as secretarias de saúde” para o atendimento dessa demanda social e pública.

2 A partir de novos entendimentos que foram sendo discutidos e construídos, chegou-se à conclusão de que o estado de saúde de uma população, comunidade, município ou país não depende apenas do indivíduo, mas da sua relação com o meio ambiente, do seu modo de vida, da sua cultura, assim como das condições econômicas e sociais”. Brasil, 2008, p. 11-12.

3 São considerados requisitos e condições para a saúde: PAZ • EDUCAÇÃO • HABITAÇÃO • ALIMENTAÇÃO RENDA • ECOSSISTEMA ESTÁVEL・RECURSOS SUSTENTÁVEIS • JUSTIÇA SOCIAL・EQÜIDADE”. Fonte: OMS, 1986. In: Brasil, 2008 , p. 12. 
Para que isso ocorra, é claro que será necessário um movimento de amplitude tal que, de um lado, os profissionais da saúde compreendam os benefícios que poderão advir, para seus pacientes mirins, de tal parceria, sensibilização e acompanhamento pedagógico que poderão receber. De outro lado, os profissionais da educação, pedagogos, também deverão estar preparados para o enfrentamento das vicissitudes que o ambiente hospitalar pode trazer, além de também estarem preparados para produzirem materiais pedagógicos alternativos, atuarem em horários diversificados dos horários escolares comuns, e atenderem um público diferenciado em função do internamento hospitalar.

Nesse contexto, ainda será preciso que os Cursos de Pedagogia atentem para esse campo de atuação que ora é posto em tela, cuidando para que em seu currículo, existam disciplinas que se orientem numa perspectiva de formação profissional mais abrangente e de estabelecimento de uma melhor aproximação e cooperação entre a escola e as unidades de saúde.

\section{2 O profissional pedagogo e o contexto hospitalar}

A prática pedagógica no ambiente hospitalar requer do profissional pedagogo uma atuação condizente com as várias situações que podem surgir naquele espaço. Por isto, afirma-se que o pedagogo está mais preparado para trabalhar com crianças hospitalizadas, por se tratar de uma especialidade que trabalhará com a sensibilidade, a afetividade, o emocional, o social, e etc. Daí a necessidade “(...) da presença de pedagogos em hospitais, com a finalidade exclusiva e específica de atender certos aspectos de natureza pedagógica do enfermo, como a de promover a continuidade da escolarização em ambiente hospitalar.” (Matos e Mugiatti, 2014, p.42).

Em sua atuação profissional no contexto hospitalar, na medida do possível, é importante que este profissional conheça o histórico da criança: o estágio da sua doença, sua família, seu contexto social. São pontos considerados importantes para planejar um trabalho pedagógico voltado a atender as especificidades de cada sujeito. Por outro lado, as propostas das atividades devem se relacionar com o lúdico e com a recreação, pois são possibilidades de práticas que podem trabalhar a arte, brincadeiras e contação de histórias, uma vez que “(...) a assistência pedagógica, na hospitalização, sugere uma ação educativa que se adapta às manifestações de cada criança/adolescente, em diferentes circunstâncias, nos enfoques didáticos, metodológicos, lúdicos e pessoais” (Matos e Mugiatti, 2014, p. 101).

Inserir a família nestas atividades é uma forma de deixar a criança mais segura e mais à vontade. Outro ponto importante é não perder o vínculo com a escola, mas ao mesmo tempo, considerar uma rotina diferente da vida escolar devido a condição de saúde em que se encontra a criança. Essas atividades devem trabalhar com o objetivo de a criança construir a sua identidade como pessoa, entender o que se passa com relação a sua saúde e de proporcionar-lhe uma forma de diminuir a ansiedade e o medo da doença. Essas atividades se justificam uma vez que

(...) são muitos os estudos sobre os efeitos negativos causados na criança pela hospitalização. Privação materna e todos os transtornos que ela determina, medo do desconhecido, sensação de punição/culpa, limitação de atividades e estimulação, aparecimento ou intensificação do sofrimento físico e despersonificação (...) (Mota, et. al., 2009, p.168-169)

O pedagogo é um profissional cuja formação habilita-o para trabalhar com práticas que estimulem novas descobertas, habilidades e competências, as quais, podem contribuir para amenizar os aspectos negativos da hospitalização para a criança.

Nesse processo, outro fator fundamental é a escuta dessa criança hospitalizada, pois é uma forma de se aproximar através do diálogo, uma oportunidade de conhecer as emoções e os sentimentos que a criança expressa naquele momento. Nesse sentido, cabe distinguir escuta de audição: 
(...) Enquanto a audição se refere à apreensão/compreensão de vozes e sons audíveis, a escuta se refere à apreensão/compreensão de expectativas e sentidos, ouvindo através das palavras as lacunas do que é dito e os silêncios, ouvindo expressões e gestos, condutas e posturas. A escuta não se limita ao campo da fala ou do falado, [mais do que isso] busca perscrutar os mundos interpessoais que constituem nossa subjetividade para cartografar o movimento das forças de vida que engendram nossa singularidade. (Ceccim, 1997, p. 31)

A atuação do pedagogo pode também ser de intermediar ações com profissionais de outras áreas, em equipe interdisciplinar, onde haja uma interação entre assistentes sociais, enfermeiros, médicos, psicólogos e demais funcionários do ambiente hospitalar. Matos e Mugiatti (2014) acreditam que

(...) só assim haverá condições favoráveis para o alcance de um nível de recuperação da saúde da criança (ou adolescente) hospitalizada de forma totalizante e participativa em que haja predominância do bom-senso, da criatividade e da criticidade, em clima interativo e de renovação permanente entre os sujeitos do processo, isto é, crianças, adolescentes, familiares e equipes atuantes, (Matos e Mugiatti, 2014, p.90)

Isto se faz importante para entender o trabalho do pedagogo naquele espaço hospitalar e ao mesmo tempo proporcionar uma ação conjunta que trará benefícios para o atendimento, fazendo com que a criança se sinta acolhida e compreendida. Tal mediação agregadora é que dará sentido e significado à constituição da pedagogia hospitalar como campo de atuação profissional.

\section{3 Aprendizados da formação profissional no estágio não-escolar}

O pedagogo para atuar no contexto hospitalar deve estar habilitado e preparado para atender a crianças que estão fora da escola por algum tempo, por motivos de saúde. A intenção é que a criança tenha uma assistência adequada e que haja continuidade dos seus estudos, dentro de suas possibilidades. Para tanto, o primeiro passo é pensar já na formação do pedagogo, especificamente, neste campo da pedagogia hospitalar como espaço profissional de sua futura atuação.

Em sua formação para docência e para a gestão de processos educativos, o pedagogo no contexto hospitalar pode ser responsável pela implementação e gerenciamento das classes hospitalares, uma vez que sua formação profissional o habilita para trabalhar com a diversidade humana, as diferentes concepções educacionais e/ou culturais - sendo, portanto, competente para identificar as diversas necessidades educacionais especiais dos educandos que se encontram hospitalizados e impedidos de frequentar o espaço escolar, as modificações e adaptações curriculares necessárias; cuja prática pedagógica será flexível no processo de acompanhamento da relação de ensino-aprendizagem.

Nestes casos, uma ação importante seria fazer um diagnóstico do aluno para saber das suas dificuldades de aprendizagem para montar estratégias que possibilitassem à criança hospitalizada o atendimento de suas necessidades educacionais, como indica a lei.

Assim, a formação profissional do pedagogo deve voltar-se para prepará-lo afim de atuar em diversas situações que a criança esteja inserida, naquele momento de sua vida. Assim, o profissional tem que estar apto a trabalhar com conteúdos educacionais, motivar as crianças no desenvolvimento de novas habilidades e desenvolver atividades que contribuam para a formação cognitiva, intelectual e social da criança (Libâneo, 1999). No contexto hospitalar isto se justifica porque há a percepção de que profissionais de saúde não possuem o mesmo preparo acadêmico dos profissionais de educação para atuarem no desenvolvimento de atividades que permitem a continuidade da aprendizagem escolar para crianças em ambientes hospitalares.

Neste sentido, é importante entender as leis que amparam a prática do pedagogo no ambiente hospitalar. A Lei de Diretrizes e Bases da Educação Nacional - LDB (Lei n 9.394/96), prevê o atendimento educacional 
feito em classes, escolas ou serviços especializados, sempre que não for possível a integração dos alunos nas classes comuns de ensino regular.

Já a Resolução CNE/CEB n 2/2001, que institui Diretrizes Nacionais para a Educação Especial na Educação Básica, em seu artigo XIII prescreve que os sistemas de ensino, mediante ação integrada com os sistemas de saúde, devem organizar o atendimento educacional especializado a alunos impossibilitados de freqüentar as aulas em razão de tratamento de saúde, e que implique a internação hospitalar, o atendimento ambulatorial ou permanência prolongada em domicílio.

Tal modalidade de ensino, na prática, significa que os hospitais devem contar, a nível municipal, por exemplo, com o apoio da Secretaria Municipal de Educação e da Secretaria Municipal de Saúde para o atendimento às determinações legais, demostrando o comprometimento com os direitos da criança e do adolescente enfermo. Neste sentido, deve-se levar em conta o valor da legislação sobre o cumprimento dos direitos das crianças hospitalizadas referente à sua continuação escolar.

De outro lado, a prática pedagógica como Estágio Supervisionado em espaço não escolar, em ambiente hospitalar, ainda na formação acadêmica para pedagogos, é de grande importância; pois contribui e proporciona a assistência cognitiva pedagógica às crianças durante o processo de internação, além de atender também a legislação que prevê a atuação do pedagogo em outros espaços - não se limitando à sala de aula.

No estágio curricular supervisionado obrigatório de educação não-escolar, realizado pelas então graduandas no Hospital Municipal de Governador Valadares MG, no segundo semestre de 2015, estas se depararam com crianças de classe média e pobres, em situação de saúde estável à grave, bem como pessoas adultas (acompanhantes das crianças) e os funcionários. Ao se analisar a parte física da pediatria onde o estágio se deu, percebeu-se que o local onde as crianças ficavam por mais tempo era desmotivador, sem cor e muitas das vezes mal higienizado - faltava manutenção e limpeza do centro de convivência, que era o ambiente onde as estagiárias realizam as atividades.

Naquela oportunidade, da realização do estágio, foram realizadas as seguintes atividades: contações de histórias, trabalhos feitos com materiais recicláveis, pinturas, desenhos e teatros. Para organizá-las, as graduandas se reuniam anteriormente para programar e providenciar os materiais que utilizariam. Antes de realizar as atividades, sempre havia a necessidade de limpar e organizar o ambiente. Uma dificuldade enfrentada era a falta de local apropriado, pois o hospital não tinha uma brinquedoteca - apesar da existência de restos de materiais pedagógicos produzidos por outros estagiários do curso de Pedagogia que por lá já haviam passado, e que estavam bem danificados. Segundo informações da enfermeira-chefe havia uma brinquedoteca móvel completa, mas o que restou foi somente a televisão.

Outro fator percebido foi a ausência de atividades recreativas para as crianças. Algumas vezes, voluntários realizavam visitas, mais em datas comemorativas: dia das crianças, natal, etc. A única distração era uma TV, que passava desenhos durante todo o dia. E naquele processo de internação, sem atividades para fazerem e às vezes recebendo um atendimento frio por parte da maioria dos profissionais, o quadro de melhora não apontava prognósticos positivos.

Também chamou a atenção a preocupação da gestão superior em relação a presença das graduadas naquele contexto hospitalar sem um profissional pedagogo de carreira do próprio hospital para acompanhamento, pois tinham ciência da legislação a respeito. Já as pessoas atendidas naquele local desconheciam o seu direito - uma vez que não eram informadas, o que induz a pensar que tal desinformação evitaria problemas para a direção do hospital. Outra percepção preocupante foi o atendimento prestado pelos funcionários, que em sua maioria, era somente com a intenção de cumprir a carga horária estipulada, esquecendo que lidavam com crianças, cujo tratamento deveria ser mais humanizado e diferenciado. 
Com relação aos acompanhantes das crianças, quase sempre as mães, percebia-se semblantes tristes, preocupação e muita vontade de conversarem. Quando tinham oportunidade falavam da doença da criança, da insatisfação do tratamento, do cansaço de muitos dias de internação, de dúvidas quanto ao tratamento. Diante deste fato, pode-se concluir que a atuação pedagógica deveria ser mais propositiva numa pediatria hospitalar, e que a formação pedagógica para atuação profissional em saúde é uma lacuna que deve ser preenchida, com urgência, nos espaços acadêmicos.

\section{CONSIDERAÇÕES FINAIS}

A proposta do trabalho realizado foi identificar a importância da atuação do pedagogo, tendo como campo de formação a pedagogia hospitalar, isto é, perceber como é importante para a criança hospitalizada receber este atendimento a partir de uma prática pedagógica que evite prejuízos em seu desenvolvimento e no aprendizado, durante o período de internação. Outro fator importante foi compreender os direitos que são assegurados à criança hospitalizada.

O estudo realizado e a prática pedagógica formadora vivenciada apontaram que o profissional pedagogo é de grande importância no ambiente hospitalar. No entanto, para que isto se torne realidade, muito há o que se percorrer. Um dos obstáculos é fazer com que os profissionais da saúde entendam que este espaço é também um campo de formação e atuação para o pedagogo, uma vez que muitos destes não reconhecem tal campo profissional como educativo.

Outro obstáculo é a própria formação profissional pedagógica, pois ainda não é uma prioridade de muitas instituições de ensino superior ter seus currículos voltados a preparar o acadêmico para atuar também em espaços não escolares - a começar pelos estágios obrigatórios, sendo fator que dificulta a percepção profissional deste campo de atuação e a presença de futuros pedagogos nestes ambientes ainda durante a formação profissional.

Consequentemente, muitas vezes, o direito a educação não é assegurado às crianças hospitalizadas. O fato de não ter o profissional da educação atuando naquele espaço, e também um ambiente adequado para que sejam realizadas as atividades pedagógicas formativas, impede o aprendizado e prejudica o desenvolvimento intelectual e cognitivo das crianças hospitalizadas.

A vivência referente ao estágio não escolar realizado na pediatria hospitalar permitiu concluir como desafiador o trabalho do pedagogo naquele contexto. De igual forma, conclui-se que é preciso priorizar o estudo da pedagogia hospitalar durante a formação do pedagogo a fim de prepará-lo para atuar com segurança e entender o seu papel naquele campo profissional. De outro lado, a realidade aponta que muitos hospitais não estão preparados para realizarem este atendimento por não ter tal profissional. Esta perspectiva pode ser mudada com a formação, efetivação e valorização profissional do trabalho pedagógico nesta área. Eis o desafio!

\section{REFERÊNCIA BIBLIOGRÁFICA}

BATISTELLA, C. Abordagens contemporâneas do conceito de saúde. In: FONSECA, A. F.; CORBO, A. M. D. O território e o processo saúde-doença. Rio de Janeiro, EPSJV; FIOCRUZ, 2007. p.51-86

BRASIL. Agência Nacional de Vigilância Sanitária. Vigilância Sanitária e Escola: parceiros na construção da cidadania/ Agência Nacional de Vigilância Sanitária. - Brasília: Anvisa, 2008.

BRASIL. Lei n 9.394, de 20 de dezembro de 1996. Estabelece as diretrizes e bases da educação nacional. Diário Oficial da República Federativa do Brasil, Poder Executivo, Brasília, DF, 20 dez. 1996. 
BRASIL. Lei n ${ }^{11.104}$, de 21 de março de 2005. Dispõe sobre a obrigatoriedade de instalação de brinquedotecas nas unidades de saúde que ofereçam atendimento pediátrico em regime de internação. Diário Oficial da República Federativa do Brasil, Poder Executivo, Brasília, DF, 21 mar. 2005.

BRASIL. Resolução n 41, de 17 de outubro de 1995. Aprova em sua íntegra o texto oriundo da Sociedade Brasileira de Pediatria, relativo aos Direitos da Criança e do Adolescente hospitalizados. CONANDA - Conselho Nacional Dos Direitos Da Criança E Do Adolescente. Diário Oficial da República Federativa do Brasil, Poder Executivo, Brasília, DF, 17 out. 1995. Seção I, p.163/9-16320.

BRASIL. Resolução CNE/CEB nº 2, de 11 de setembro de 2001. Institui Diretrizes Nacionais para a Educação Especial na Educação Básica. Diário Oficial da República Federativa do Brasil, Poder Executivo, Brasília, DF, 11 set. 2001.

BRASIL. Ministério da Educação. Classe hospitalar e atendimento pedagógico domiciliar: estratégias e orientações. Secretaria de Educação Especial. - Brasília: MEC - SEESP, 2002.

CECCIM, R. B. Criança hospitalizada: a atenção integral como uma escuta à vida. In: CECCIM, R.B., CARVALHO, P. R. A. (Org.). Criança hospitalizada: atenção integral como escuta à vida. Porto Alegre: Editora da UFRGS, 1997, p. 27-41.

LIBÂNEO, J. C. Pedagogia e pedagogos, para quê? 2.ed. São Paulo: Cortez, 1999.

MARANHAO, D. G. O cuidado com o elo entre saúde e educação. Cad. Pesqui. [online]. n.111, p.115-133, dez. 2000.

MATOS, E. L. M; MUGIATTI, M. M. T. F. Pedagogia Hospitalar: A humanização integrando educação e saúde. $7^{\mathrm{a}}$.ed. - Petropólis, RJ: Vozes, 2014

MOTA, M. C. et. al.. Brinquedoteca Hospitalar “Nosso Cantinho”. Relato de uma experiência de brincar. Belo Horizonte, MG: Editora UFMG; Pró-Reitoria de Extensão / UFMG, 1ª.ed..atualizada, 2009, p.167-179.

PINEL, H. Pedagogia Hospitalar numa perspectiva inclusivista. In: Pedagogia Hospitalar: um enfoque fenomenológico existencial / organização, Alex Sandro C. Sant`Ana, Hiran Pinel, Paulo Roque Colodete Teresina, Piauí: Edufpi, 2015. p. 10-41.

SCLIAR, M. História do Conceito de Saúde. PHYSIS: Rev. Saúde Coletiva, Rio de Janeiro, 17(1): 29-41, 2007. 